\title{
Absence of Disproportionately Enlarged Subarachnoid Space Hydrocephalus, a Sharp Callosal Angle, or Other Morphologic MRI Markers Should Not Be Used to Exclude Patients with Idiopathic Normal Pressure Hydrocephalus from Shunt Surgery
}

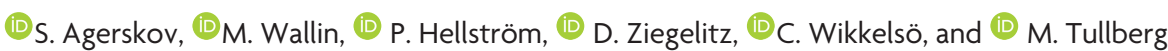

\begin{abstract}
BACKGROUND AND PURPOSE: Several studies have evaluated the use of MR imaging markers for the prediction of outcome after shunt surgery in idiopathic normal pressure hydrocephalus with conflicting results. Our aim was to investigate the predictive value of a number of earlier proposed morphologic MR imaging markers in a large group of patients with idiopathic normal pressure hydrocephalus.
\end{abstract}

MATERIALS AND METHODS: One hundred sixty-eight patients (mean age, $70 \pm 9.3$ years) with idiopathic normal pressure hydrocephalus, subjected to standardized quantification of clinical symptoms before and after shunt surgery, were included in the study. Outcome was calculated using a composite score. Preoperative T1, FLAIR, and flow-sensitive images were analyzed regarding the presence of 13 different morphologic MR imaging markers.

RESULTS: The median Evans index was 0.41 (interquartile range, 0.37-0.44). All patients had an aqueductal flow void sign present and white matter hyperintensities. The median callosal angle was $68.8^{\circ}$ ( interquartile range, $57.7^{\circ}-80.8^{\circ}$ ). Dilated Sylvian fissures were found in $69 \%$; focally dilated sulci, in $25 \%$; and widening of the interhemispheric fissure, in $55 \%$. Obliteration of the sulci at the convexity was found in $36 \%$, and $36 \%$ of patients were characterized as having disproportionately enlarged subarachnoid space hydrocephalus. Sixty-eight percent of patients improved after surgery. None of the investigated MR imaging markers were significant predictors of improvement after shunt surgery.

CONCLUSIONS: Disproportionately enlarged subarachnoid space hydrocephalus, a small callosal angle, and the other MR imaging markers evaluated in this study should not be used to exclude patients from shunt surgery. These markers, though they may be indicative of idiopathic normal pressure hydrocephalus, do not seem to be a part of the mechanisms connected to the reversibility of the syndrome.

ABBREVIATIONS: DESH = disproportionately enlarged subarachnoid space hydrocephalus; $\mathrm{El}=$ Evans index; $\mathrm{iNPH}=$ idiopathic normal pressure hydrocephalus

\begin{abstract}
diopathic normal pressure hydrocephalus (iNPH) is a syndrome of gait and balance disturbances, cognitive dysfunction, and urinary incontinence seen predominantly in the elderly population. ${ }^{1-5}$ Enlarged ventricles on CT or MR imaging are required for the diagnosis, and different radiologic evaluation techniques have been used to increase the diagnostic and predictive accuracy ever since its first description by Adams et al. ${ }^{6}$ Today, MR imaging is considered the standard radiologic method, and MR imaging-
\end{abstract}

Received September 5, 2018; accepted after revision October 24

From the Hydrocephalus Research Unit (S.A., M.W., P.H., C.W., M.T.), Department of Clinical Neuroscience and Rehabilitation, Institute of Neuroscience and Physiology, and Department of Neuroradiology (D.Z.), Institute of Clinical Sciences, Sahlgrenska Academy, University of Gothenburg, Gothenburg, Sweden.

This work was supported by grants from the Edit Jacobson Foundation, the Rune and Ulla Almlövs Foundation for Neurological Research, and the Gothenburg Foundation for Neurological Research.

Please address correspondence to Simon Agerskov, MD, Hydrocephalus Research Unit, Institute of Neuroscience and Physiology, Department of Clinical Neuroscience, Sahlgrenska Academy, University of Gothenburg, Sahlgrenska University Hospital, 41345 Gothenburg, Sweden; e-mail: simon.agerskov@vgregion.se

http://dx.doi.org/10.3174/ajnr.A5910 based criteria for diagnosing the condition are incorporated in the international and Japanese diagnostic guidelines. ${ }^{1,2}$

In the international guidelines, ventriculomegaly with an Evans index (EI) of $>0.3$ in combination with at least 1 of 4 supportive findings is required for the diagnosis of probable iNPH. ${ }^{2}$ The Japanese criteria instead emphasize the finding of disproportionately enlarged subarachnoid space hydrocephalus (DESH), requiring it for the diagnosis of probable iNPH if no Tap-Test or CSF drainage test is performed. ${ }^{1}$

The connection between radiologic findings and symptoms in iNPH has also recently been reinforced with the use of a composite scale score including morphologic CT findings in patients with iNPH. ${ }^{7}$

The use of morphologic MR imaging markers for selecting appropriate shunt surgery candidates has been investigated, but results vary; the use of these markers for predictive purposes is still disputed. ${ }^{8-12} \mathrm{DESH}^{13}$ has won support as a prognostic marker, ${ }^{14}$ most recently by Shinoda et al, ${ }^{15}$ who developed a 10 -point grading scale to aid in patient selection for surgery. Virhammar 
Table 1: Demographic data of 168 patients with iNPH

\begin{tabular}{lc}
\multicolumn{1}{c}{ Data } \\
\hline Age (mean) (SD) (yr) & $71(9.3)$ \\
Male/female (\%) & $61: 39$ \\
Symptom duration (mean) (SD) (mo) & $47(59)$ \\
Comorbidity (\%) & \\
$\quad$ Hypertension & 49 \\
Cardiovascular disease & 26 \\
Diabetes mellitus & 15 \\
\hline
\end{tabular}

et $\mathrm{al}^{8,16}$ reported that the presence of DESH, a narrow callosal angle $\left(<63^{\circ}\right)$, and dilation of the temporal horns were predictors of good surgical outcome.

The use of morphologic MR imaging markers for predicting outcome after shunt surgery in patients with iNPH requires further investigation. Hence, the aim of this study was to investigate the association between 13 morphologic MR imaging markers and postoperative outcome in a large consecutive cohort of patients with iNPH subjected to a detailed clinical evaluation.

\section{MATERIALS AND METHODS}

One-hundred sixty-eight patients consecutively diagnosed with iNPH in accordance with the international guidelines ${ }^{2}$ who underwent shunt surgery between 2006 and 2013 were included in the study. Patients were included if they had a complete preoperative MR imaging scan including volumetric T1, FLAIR, and flow-sensitive T2 sequences. If substantial movement artifacts were present on any of the sequences, the patient was excluded. Demographic data of the patient group are shown in Table 1.

\section{Clinical Evaluation}

All patients underwent detailed clinical examinations by a neurologist and a physiotherapist preoperatively and 3-6 months postoperatively following standardized protocols. ${ }^{5}$ To evaluate outcome after shunt surgery, we created a composite score incorporating 4 continuous measures based on 2 gait tests and 2 cognitive tests (the Timed 10-Meter Walk Test ${ }^{17}$; the Timed Up and Go Test ${ }^{18}$; the Identical Forms Test, measuring perceptual speed and accuracy; and the Bingley Memory Test $\left.{ }^{19}\right)$. Each score was standardized into a 0-100 scale with 0 representing the worst possible performance and 100 equaling the mean performance of healthy individuals at 70 years of age. .,17,20 $^{-12}$ The composite score was calculated using the mean value of the 4 included tests, and the difference between the pre- and postoperative score constituted the outcome for each patient. Patients were classified as improved if their score increased by $\geq 5$ points. ${ }^{4,5}$ All shunts were functioning at the time of the postoperative clinical evaluation.

\section{Imaging}

All preoperative MR imaging scans were performed using a 1.5T Intera (Philips Healthcare, Best, the Netherlands) or a $1.5 \mathrm{~T}$ Achieva dStream (Philips Healthcare) scanner. The imaging sequences were reformatted and analyzed using an Advantage Workstation 2.0 (GE Healthcare, Milwaukee, Wisconsin). The imaging protocol consisted of the following: 1) a sagittal T1weighted volume sequence with $\mathrm{TR} / \mathrm{TE}=25 / 4.6 \mathrm{~ms}$, flip angle $=$ $30^{\circ}, \mathrm{FOV}=260 \times 260 \times 190 \mathrm{~mm}^{3}$, matrix $=260 \times 259$, and 380 overcontiguous 1-mm slices; 2) a transaxial FLAIR sequence with $\mathrm{TR} / \mathrm{TE}=9000 / 100 \mathrm{~ms}$, inversion recovery delay $=2500 \mathrm{~ms}$,
FOV $=230 \times 230 \times 230 \mathrm{~mm}^{3}$, matrix $=192 \times 192,44$ sections, 3-mm slice thickness, and no gap; 3 ) a flow-sensitive sagittal TSE sequence with $\mathrm{TR} / \mathrm{TE}=10,238 / 300 \mathrm{~ms}, \mathrm{FOV}=230 \times 230 \times 38$ $\mathrm{mm}^{3}$, matrix $=384 \times 284$, thirteen sections, 2 -mm slice thickness, and 1-mm gap; and 4) an aqueduct-centered turbo field echo sequence with $\mathrm{TR} / \mathrm{TE}=7.7 / 3.8 \mathrm{~ms}$, flip angle $=60^{\circ}$, FOV $=$ $150 \times 150 \times 15 \mathrm{~mm}^{3}$, matrix $=256 \times 256$ with 75 overcontiguous 0.2 -mm slices.

On the T1-weighted volume sequences, a line connecting the anterior and posterior commissures was defined (ie, the anterior/ posterior commissure plane). ${ }^{8,16,21}$ The T1-weighted $3 \mathrm{D}$ volumes were then reformatted generating coronal images perpendicular to and transaxial images parallel to the anterior/posterior commissure plane. All reformatted T1-weighted volume sequences had voxel sizes of $1 \times 1 \times 1 \mathrm{~mm}$ and were used with the FLAIR, TSE, and turbo field echo sequences in the image analyses.

In total, 13 imaging markers were analyzed (Figure).

The EI was measured on transaxial T1-weighted images as the index between the maximum diameter of the frontal horns and the maximum inner skull diameter in the slice above the foramen of Monro (Fig $A$ ). Then, the maximum diameter of the temporal horns was recorded bilaterally (Fig $B$ ). The callosal angle was analyzed on coronal T1 images at the level of the posterior commissure (Fig C). ${ }^{16}$

Coronal T1 images were also used to measure the widest diameter of the third ventricle between the anterior and posterior commissures (Fig D). On sagittal T1 slices, the widest anteroposterior midline diameter of the fourth ventricle was determined along a line perpendicular to the posterior border of the brain stem (Fig $E$ ).

Obliteration of the high-convexity sulci was assessed on transaxial T1 images and graded as obliterated if no sulci were distinguishable on the 10 most cranial slices covering the vertex (Fig $F)$.

The presence of focally enlarged (transport) sulci was analyzed on transaxial and coronal T1 series. The sulci were only determined as focally widened if there were no signs of general cortical atrophy, the sulcal widening was asymmetric, and the affected sulci lacked connection with the Sylvian fissure. The number of focally widened sulci was recorded (Fig $G$ ).

Dilation of the Sylvian fissures was measured on coronal T1 images using an ordinal scale (Fig $H$ ). ${ }^{16,22}$ Widening of the anterior part of the interhemispheric fissure was estimated on transaxial T1 images using a 3-step ordinal scale (Fig $I$ ). The flow void phenomenon in the cerebral aqueduct and fourth ventricle (flow void sign) was evaluated and graded using the ordinal scale developed by Algin et $\mathrm{al}^{23}$ and later modified by Virhammar et al (Fig $J) .{ }^{8}$ Periventricular and deep white matter hyperintensities were analyzed on transaxial FLAIR series using the scale developed by Fazekas et al. ${ }^{24}$

DESH was considered present if patients showed signs of Sylvian fissure dilation (ordinal rating 1 or 2) in conjunction with obliterated sulci at the high convexity.

Analyses were performed in a retrospective manner with investigators blinded to the patients' clinical data. To ensure reproducibility, 2 authors (S.A., M.W.) analyzed all variables independently in 10 randomly selected patients and calculated interrater 




FIGURE. Morphologic MR imaging markers analyzed in 168 patients with iNPH preoperatively. A, Evans index. $B$, Maximum width of the temporal horns. C, Callosal angle. D, Maximum width of the third ventricle. E, Maximum anteroposterior diameter of the fourth ventricle. $F$, Obliteration of sulci at the vertex. $G$, Transport of sulci on transaxial and coronal images (left-right). $H$, Width of the Sylvian fissures graded 0 to $1-2$ (left-right). I, Width of the interhemispheric fissure graded 0 to $1-2$ (left-right). J, Flow void sign graded 1 to $2-3$ (left-right, 0 not shown in the figure).

reliability. In cases in which discrepancies occurred, the variables were redefined and re-evaluated until an interrater reliability of $>0.7$ was achieved. The development of the image-analysis protocol was supervised by an experienced neuroradiologist (D.Z.)
Table 2: Pre- and postoperative gait, cognitive, and total scores in 168 patients with iNPH

\begin{tabular}{lccc}
\hline & Preoperative & Postoperative & $\boldsymbol{P}$ \\
\hline Gait (median) (IQR) & $38(17-61)$ & $66(43-87)$ & $<.001$ \\
Cognition (median) (IQR) & $35(19-66)$ & $50(20-75)$ & $<.001$ \\
Total (median) (IQR) & $39(23-63)$ & $57(38-76)$ & $<.001$ \\
\hline
\end{tabular}

Note:-IQR indicates interquartile range.

who also assisted in the refinement of MR imaging markers as required until the interrater reliability ratings were sufficient. In addition, $20 \%$ of patient scans were randomly selected and reevaluated by one of the authors (S.A.) to calculate the test-retest reliability, which was $>0.8$ for all variables.

\section{Statistics}

All statistical tests were performed using nonparametric procedures. Differences in distributions among binary variables were tested using the McNemar test. Tests of differences between groups for ordinal and interval data were performed using the Wilcoxon rank sum test. Correlations were tested using Spearman rank correlations. Associations between outcome and analyzed MR imaging variables were assessed using logistic regression models with results presented as odds ratios with $95 \%$ confidence intervals. Interrater and test-retest reliability was calculated using intraclass correlation coefficients for continuous variables and the weighted/unweighted Cohen $\kappa$ for ordinal and nominal variables, respectively. Statistical significance was $P<.05$. All calculations were performed in SPSS, Version 24.0, released in 2014 (IBM, Armonk, New York).

\section{Ethical Considerations}

The data collection was approved by the Ethics Committee for Medical Research at Gothenburg University, with written informed consent obtained from all participants or close relatives.

\section{RESULTS}

\section{Surgical Outcome}

Sixty-eight percent $(n=115)$ of the patients improved after shunt surgery, $23 \%(n=39)$ were unchanged, and conditions of $8 \%$ $(n=14)$ deteriorated. Improvement was most pronounced in the gait domain (Table 2).

\section{Preoperative MR Imaging Findings and Outcome}

All patients had an EI of $>0.3$, a present flow void sign, white matter hyperintensities, and a callosal angle of $<90^{\circ}$ (Table 3 ). Dilation of the Sylvian fissures was found in $72 \%$, while focal dilation of the supra-Sylvian sulci and obliteration of sulci at the high convexity were more uncommon $(28 \%-36 \%)$. Thirty-nine percent had a callosal angle of $<63^{\circ}$ (responders, $39 \%$; nonresponders, $38 \% ; P=$ not significant). There were no significant differences between responders and nonresponders in the distribution of any of the morphologic MR imaging markers or in the prevalence of periventricular and deep white matter changes. Furthermore, the severity of white matter changes did not have any effect on postoperative outcome.

In the logistic regression models adjusted for age and sex, no MR imaging marker was significantly associated with postoperative improvement, neither for the total score nor for any of the subdomain scores. 
Table 3: Preoperative morphologic MRI markers in 168 patients with iNPH

\begin{tabular}{|c|c|c|c|c|c|}
\hline All Patients & No. & $\begin{array}{c}\text { Median/\% } \\
\text { (IQR) }\end{array}$ & $\begin{array}{l}\text { Improved } \\
\text { (Median/\%) }\end{array}$ & $\begin{array}{c}\text { Not } \\
\text { Improved } \\
\text { (Median/\%) }\end{array}$ & $P$ \\
\hline Evans index & & $0.41(0.37-0.44)$ & 0.40 & 0.39 & NS \\
\hline Temporal horns (mm) & & $9.1(7.5-11.0)$ & 9.0 & 9.1 & NS \\
\hline Callosal angle & & $68^{\circ}\left(56^{\circ}-81^{\circ}\right)$ & $68^{\circ}$ & $69^{\circ}$ & NS \\
\hline Third ventricle width (mm) & & $15.5(13.3-18)$ & 15.4 & 16.5 & NS \\
\hline Fourth ventricle width (mm) & & $14.7(13.2-16.3)$ & 14.7 & 14.6 & NS \\
\hline \multirow[t]{4}{*}{ Transport sulci (\%) } & 0 & 72 & 75 & 68 & NS \\
\hline & 1 & 17 & 19 & 11 & \\
\hline & 2 & 8 & 6 & 14 & \\
\hline & $>2$ & 3 & 0 & 7 & \\
\hline \multirow[t]{3}{*}{ Dilated interhemispheric fissure (\%) } & 0 & 42 & 45 & 38 & NS \\
\hline & 1 & 49 & 45 & 54 & \\
\hline & 2 & 9 & 10 & 8 & \\
\hline Obliterated sulci at vertex (\%) & & 36 & 36 & 35 & NS \\
\hline \multirow[t]{3}{*}{ Dilated Sylvian fissure (\%) } & 0 & 28 & 31 & 22 & \\
\hline & 1 & 45 & 45 & 46 & \\
\hline & 2 & 27 & 24 & 32 & \\
\hline DESH present (\%) & & 36 & 36 & 34 & NS \\
\hline \multirow[t]{4}{*}{ Flow void sign (\%) } & 0 & 0 & 0 & 0 & \\
\hline & 1 & 30 & 30 & 26 & \\
\hline & 2 & 42 & 37 & 47 & \\
\hline & 3 & 28 & 35 & 27 & \\
\hline \multirow[t]{4}{*}{ PVH (\%) } & 0 & 0 & 0 & 0 & NS \\
\hline & 1 & 57 & 58 & 49 & \\
\hline & 2 & 26 & 25 & 29 & \\
\hline & 3 & 17 & 17 & 22 & \\
\hline \multirow[t]{4}{*}{ DWMH (\%) } & 0 & 0 & 0 & 0 & NS \\
\hline & 1 & 46 & 47 & 45 & \\
\hline & 2 & 37 & 42 & 29 & \\
\hline & 3 & 17 & 11 & 26 & \\
\hline
\end{tabular}

Note:-PVH indicates periventricular hyperintensities; DWMH, deep white matter hyperintensities; NS, not significant; $\mathrm{IQR}$, interquartile range.

Table 4: Correlation coefficients between clinical symptom severity and preoperative MRI findings in 168 patients with iNPH

\begin{tabular}{lccc} 
& $\begin{array}{c}\text { Total } \\
\text { Symptom } \\
\text { Score }\end{array}$ & $\begin{array}{c}\text { Gait } \\
\text { Score }\end{array}$ & $\begin{array}{c}\text { Cognition } \\
\text { Score }\end{array}$ \\
\hline El & -0.09 & -0.04 & -0.12 \\
Temporal horns (mean) & -0.30 & 0.1 & $-0.15^{\mathrm{a}}$ \\
Interhemispheric fissure & -0.20 & -0.04 & -0.04 \\
Callosal angle & 0.17 & 0.13 & 0.16 \\
Third ventricle & -0.19 & $-0.25^{\mathrm{a}}$ & 0.07 \\
Sylvian fissures (mean) & -0.1 & $-0.15^{\mathrm{a}}$ & 0.08 \\
Obliterated sulci & 0.19 & 0.18 & 0.13 \\
DESH & 0.11 & 0.06 & 0.11 \\
Flow void & 0.03 & 0.09 & -0.03 \\
Fourth ventricle & $-0.20^{\mathrm{a}}$ & $-0.20^{\mathrm{a}}$ & 0.16 \\
Transport sulci & 0.07 & 0.18 & 0.08 \\
PVH & $-0.26^{\mathrm{a}}$ & $-0.22^{\mathrm{a}}$ & $-0.23^{\mathrm{a}}$ \\
DWMH & $-0.22^{\mathrm{a}}$ & $-0.21^{\mathrm{a}}$ & $-0.17^{\mathrm{a}}$ \\
\hline
\end{tabular}

Note:- $\mathrm{PVH}$ indicates periventricular hyperintensities; DWMH, deep white matter hyperintensities.

${ }^{a} p<.05$.

\section{Correlations with Clinical Symptoms}

A few measures were significantly correlated with preoperative clinical symptoms. However, the correlations were all weak (ie, $<.30$ ) (Table 4).

\section{DISCUSSION}

In this study of 168 patients with iNPH, we analyzed a number of proposed MR imaging markers for the prediction of outcome after shunt surgery. We could not show significant associations between any of the analyzed MR imaging markers and postoperative improvement, nor were there significant differences in the presence of proposed imaging markers between improved and nonimproved patients. Specifically, a small callosal angle or the finding of DESH was not associated with a favorable outcome.

The lack of correlation between morphologic MR imaging markers and postoperative improvement corroborates some earlier studies ${ }^{9,12,25}$ and contradicts other publications that have reported significant associations between postoperative improvement and the presence of a narrow callosal angle, ${ }^{16}$ the DESH phenomenon, ${ }^{15,16}$ and dilation of the temporal horns. ${ }^{8}$

A possible explanation for the different results regarding the predictive value of morphologic imaging markers reported here compared with many earlier studies could be the selection of patients. We based the iNPH diagnosis and decision to perform shunt surgery on clinical and radiologic criteria, and only in patients in whom the outcome of shunt surgery was considered uncertain was the CSF Tap-Test or lumbar infusion test used as a supplementary test. Lumbar puncture was performed for intracranial pressure measurement and exclusion of other disorders. Furthermore, with the exception of the EI, none of the imaging markers were specifically required for diagnosis. Diagnostic criteria requiring the presence of DESH, a positive response to CSF drainage, or an increased resistance to CSF outflow such as the Japanese guidelines, ${ }^{1}$ entail a possible selection bias in which patients who would potentially improve after shunt surgery were excluded from studies. We believe that the inclusion of patients with iNPH in our study is more general with less selection bias compared with many earlier studies, which could explain differences in results reported. Overall, we consider the patient sample representative, and the results reported here are robust. Moreover, our results are in agreement with those of Craven et $\mathrm{al}^{12}$; and in a recent report by Benedetto et $\mathrm{al}^{26}$ using a CT-based method to assess DESH, there were no differences between patients who improved and those who did not improve after shunt surgery.

Another possible cause of the contradictory results in some earlier studies might be the use of different outcome measures. In our study, the aim was to use a sensitive outcome measure similar to the iNPH scale designed by Hellström et $\mathrm{al}^{4}$ in order to base our calculations on improvements in continuous variables that are norm-based and thus reproducible. Many of the previous studies have used the modified Rankin Scale, which was developed for use in patients with stroke and does not measure symptom severity in 
iNPH but instead provides a general measure of disability. ${ }^{27}$ Other groups have applied outcome scales based on ordinal or nominal ratings, ${ }^{8,10,15}$ making a direct comparison with the results presented here more difficult. To maximize the sensitivity and validity of results, one should use quantitative outcome measures if possible. ${ }^{4}$ Using outcome measurements that are blunt or potentially not measuring an actual improvement of hydrocephalic symptoms (such as the modified Rankin Scale) increases the risk of misjudging proposed imaging markers and their use as predictors of postoperative outcome.

The prevalence of DESH in this study is lower in comparison with previous publications. ${ }^{8,13,28}$ This outcome might be because in accordance with the international diagnostic guidelines, the components of the DESH phenomenon were not part of the diagnostic criteria for the evaluated iNPH group. Furthermore, we graded sulcal compression at the vertex as obliterated or not, meaning that patients who did not show complete sulcal obliteration but still had some degree of compression in conjunction with Sylvian dilation were graded as not having DESH. However, DESH prevalence figures in patients with iNPH of around $30 \%$ have previously been reported, ${ }^{12}$ and the same authors did not find any support for DESH as a predictive factor for shunt responsiveness, confirming our results.

While DESH is a common finding in patients with $\mathrm{iNPH}$ and can aid in diagnosing the disorder, this study implies that it should be used neither as an obligatory diagnostic finding nor as a predictive marker, given the risk of excluding patients from shunt surgery who might benefit from the procedure.

All patients in our study presented with an EI of $>0.3$, in agreement with the international guidelines. ${ }^{2}$ In addition, the ventriculomegaly also involved the third and fourth ventricles in most patients, corroborating previous findings. ${ }^{9}$ The enlargement of the third and fourth ventricles also correlated significantly, albeit weakly, with the gait symptom score. Although these findings could not significantly predict good postoperative outcome, they are still important to consider from a pathophysiologic aspect. Infratentorial periventricular structures might be involved in the development of clinical symptoms. ${ }^{5,29,30}$

All patients presented with white matter changes on preoperative MR imaging. The severity of these changes did not differ significantly between shunt responders and nonresponders in this study; this result corroborates previously published work ${ }^{8,31}$ and reinforces the theory that the extent of white matter damage should not exclude patients from shunt surgery.

Our findings of only weak correlations between ventricular dilation or white matter changes on the one hand and symptom severity on the other differ markedly from a recent study reporting an association between $8 \mathrm{CT}$-based imaging markers and the severity of clinical symptoms. ${ }^{7}$ The cited study used the iNPH grading scale, ${ }^{4}$ and the statistical analysis was performed using linear regression modeling, which we were unable to reproduce given the absence of a linear relationship between our dependent and independent variables and non-normal data distribution.

Our findings support the view that clinical improvement in iNPH after shunt surgery is mainly attributed to increased metabolism and extracellular fluid flow in predominantly periventricu- lar regions of the brain and not morphologic changes as measured on structural MR imaging. Support for this notion comes from imaging studies of perfusion ${ }^{32-35}$ and diffusion ${ }^{29,36}$ and CSF biomarker studies ${ }^{37,38}$ as well as a recent study indicating reduced glymphatic clearance in patients with iNPH. ${ }^{39}$

The results reported here imply that morphologic MR imaging markers only correlate with symptom severity in a limited way and cannot predict postoperative outcome. To find reliable markers for selecting appropriate candidates for shunt surgery, focus should be turned to the use of higher order MR imaging analyses, such as diffusion- and perfusion-based techniques as well as combinations of MR imaging and biochemical methods. Further studies are needed in this area.

\section{Strengths and Weaknesses}

The strengths of this study are the large consecutively included patient population, a prospective data collection, and the detailed assessment of clinical outcome after shunt surgery. We also realigned all scans before the subsequent analysis, thus minimizing the effects of possible misalignment. In addition, with the exception of the EI, the analysis of all variables was performed after the diagnosis of $\mathrm{iNPH}$ was made, thus reducing the risk of selection bias.

The main limitations are the retrospective image analysis and the fact that a group of patients diagnosed before $2006 \mathrm{had}$ to be excluded because they lacked MR imaging scans that fulfilled our inclusion criteria. The excluded patients did not differ in any demographic data nor in our outcome score compared with our study population. In all, we consider the evaluated patient sample and the results reported here to be representative.

\section{CONCLUSIONS}

DESH, a small callosal angle, and the other MR imaging markers evaluated in this study should not be used to exclude patients from shunt surgery. These markers, though they may be indicative of iNPH, do not seem to be a part of the mechanisms connected to the reversibility of the syndrome.

Disclosures: Simon Agerskov—RELATED: Grant: Rune and Ulla Amlöv Foundation Edit Jacobson Foundation, Gothenburg Foundation for Neurological Research. Per Hellström-UNRELATED: Employment: Clinical Neuropsychologist at Sahlgrenska University Hospital. Carsten Wikkelsö-UNRELATED: Board Membership: Associate Editor of Acta Neurologica Scandinavica.

\section{REFERENCES}

1. Mori E, Ishikawa M, Kato T, et al; Japanese Society of Normal Pressure Hydrocephalus. Guidelines for management of idiopathic normal pressure hydrocephalus: second edition. Neurol Med Chir (Tokyo) 2012;52:775-809 CrossRef Medline

2. Relkin N, Marmarou A, Klinge P, et al. Diagnosing idiopathic normal-pressure hydrocephalus. Neurosurgery 2005;57(3 Suppl):S416; discussion ii-v Medline

3. Blomsterwall E, Svantesson U, Carlsson U, et al. Postural disturbance in patients with normal pressure hydrocephalus. Acta Neurol Scand 2000;102:284-91 CrossRef Medline

4. Hellström P, Klinge P, Tans J, et al. A new scale for assessment of severity and outcome in iNPH. Acta Neurol Scand 2012;126:229-37 CrossRef Medline

5. Agerskov S, Hellström P, Andrén K, et al. The phenotype of idiopathic normal pressure hydrocephalus: a single center study of 429 patients. J Neurol Sci 2018;391:54-60 CrossRef Medline 
6. Adams RD, Fisher CM, Hakim S, et al. Symptomatic occult hydrocephalus with normal cerebrospinal-fluid pressure: a treatable syndrome. $N$ Engl J Med 1965;273:117-26 CrossRef Medline

7. Kockum K, Lilja-Lund O, Larsson EM, et al. The idiopathic normalpressure hydrocephalus Radscale: a radiological scale for structured evaluation. Eur J Neurol 2018;25:569-76 CrossRef Medline

8. Virhammar J, Laurell K, Cesarini KG, et al. Preoperative prognostic value of MRI findings in 108 patients with idiopathic normal pressure hydrocephalus. AJNR Am J Neuroradiol 2014;35:2311-18 CrossRef Medline

9. Wikkelsö C, Andersson H, Blomstrand C, et al. Computed tomography of the brain in the diagnosis of and prognosis in normal pressure hydrocephalus. Neuroradiology 1989;31:160-65 CrossRef Medline

10. Kazui H, Mori E, Ohkawa S, et al. Predictors of the disappearance of triad symptoms in patients with idiopathic normal pressure hydrocephalus after shunt surgery. J Neurol Sci 2013;328:64-69 CrossRef Medline

11. Halperin JJ, Kurlan R, Schwalb JM, et al. Practice guideline: idiopathic normal pressure hydrocephalus-response to shunting and predictors of response: Report of the Guideline Development, Dissemination, and Implementation Subcommittee of the American Academy of Neurology. Neurology 2015;85:2063-71 CrossRef Medline

12. Craven CL, Toma AK, Mostafa T, et al. The predictive value of DESH for shunt responsiveness in idiopathic normal pressure hydrocephalus. J Clin Neurosci 2016;34:294-98 CrossRef Medline

13. Hashimoto M, Ishikawa M, Mori E, et al; Study of INPH on neurological improvement (SINPHONI). Diagnosis of idiopathic normal pressure hydrocephalus is supported by MRI-based scheme: a prospective cohort study. Cerebrospinal Fluid Res 2010;7:18 CrossRef Medline

14. Garcia-Armengol R, Domenech S, Botella-Campos C, et al. Comparison of elevated intracranial pressure pulse amplitude and disproportionately enlarged subarachnoid space (DESH) for prediction of surgical results in suspected idiopathic normal pressure hydrocephalus. Acta Neurochir (Wien) 2016;158:2207-13 CrossRef Medline

15. Shinoda N, Hirai O, Hori S, et al. Utility of MRI-based disproportionately enlarged subarachnoid space hydrocephalus scoring for predicting prognosis after surgery for idiopathic normal pressure hydrocephalus: clinical research. J Neurosurg 2017;127:1436-42 CrossRef Medline

16. Virhammar J, Laurell K, Cesarini KG, et al. The callosal angle measured on MRI as a predictor of outcome in idiopathic normal-pressure hydrocephalus. J Neurosurg 2014;120:178-84 CrossRef Medline

17. Steffen TM, Hacker TA, Mollinger L. Age- and gender-related test performance in community-dwelling elderly people: Six-Minute Walk Test, Berg Balance Scale, Timed Up \& Go Test, and gait speeds. Phys Ther 2002;82:128-37 CrossRef Medline

18. Podsiadlo D, Richardson S. The timed "Up \& Go": a test of basic functional mobility for frail elderly persons. J Am Geriatr Soc 1991; 39:142-48 CrossRef Medline

19. Tullberg M, Rosengren L, Blomsterwall E, et al. CSF neurofilament and glial fibrillary acidic protein in normal pressure hydrocephalus. Neurology 1998;50:1122-27 CrossRef Medline

20. Solana E, Poca MA, Sahuquillo J, et al. Cognitive and motor improvement after retesting in normal-pressure hydrocephalus: a real change or merely a learning effect? J Neurosurg 2010;112:399-409 CrossRef Medline

21. Ishii K, Kanda T, Harada A, et al. Clinical impact of the callosal angle in the diagnosis of idiopathic normal pressure hydrocephalus. Eur Radiol 2008;18:2678-83 CrossRef Medline

22. Kitagaki $\mathrm{H}$, Mori $\mathrm{E}$, Ishii $\mathrm{K}$, et al. CSF spaces in idiopathic normal pressure hydrocephalus: morphology and volumetry. AJNR Am J Neuroradiol 1998;19:1277-84 Medline
23. Algin O, Hakyemez B, Taskapilioglu O, et al. Morphologic features and flow void phenomenon in normal pressure hydrocephalus and other dementias: are they really significant? Acad Radiol 2009;16: 1373-80 CrossRef Medline

24. Fazekas F, Chawluk JB, Alavi A, et al. MR signal abnormalities at $\mathbf{1 . 5}$ $T$ in Alzheimer's dementia and normal aging. AJR Am J Roentgenol 1987;149:351-56 CrossRef Medline

25. Virhammar J, Laurell K, Cesarini KG, et al. Increase in callosal angle and decrease in ventricular volume after shunt surgery in patients with idiopathic normal pressure hydrocephalus. J Neurosurg 2018 Feb 2:1-6. [Epub ahead of print] CrossRef Medline

26. Benedetto N, Gambacciani C, Aquila F, et al. A new quantitative method to assess disproportionately enlarged subarachnoid space (DESH) in patients with possible idiopathic normal pressure hydrocephalus: the SILVER index. Clin Neurol Neurosurg 2017;158: 27-32 CrossRef Medline

27. Wilson JT, Hareendran A, Hendry A, et al. Reliability of the modified Rankin Scale across multiple raters: benefits of a structured interview. Stroke 2005;36:777-81 CrossRef Medline

28. Ishikawa M, Oowaki H, Takezawa M, et al. Disproportionately enlarged subarachnoid space hydrocephalus in idiopathic normalpressure hydrocephalus and its implication in pathogenesis. Acta Neurochir Suppl 2016;122:287-90 CrossRef Medline

29. Jurcoane A, Keil F, Szelenyi A, et al. Directional diffusion of corticospinal tract supports therapy decisions in idiopathic normal-pressure hydrocephalus. Neuroradiology 2014;56:5-13 CrossRef Medline

30. Lee $\mathrm{PH}$, Yong SW, Ahn YH, et al. Correlation of midbrain diameter and gait disturbance in patients with idiopathic normal pressure hydrocephalus. J Neurol 2005;252:958 -63 CrossRef Medline

31. Tullberg M, Jensen C, Ekholm S, et al. Normal pressure hydrocephalus: vascular white matter changes on MR images must not exclude patients from shunt surgery. AJNR Am J Neuroradiol 2001;22:1665-73 Medline

32. Ziegelitz D, Starck G, Kristiansen D, et al. Cerebral perfusion measured by dynamic susceptibility contrast MRI is reduced in patients with idiopathic normal pressure hydrocephalus. J Magn Reson Imaging 2014;39:1533-42 CrossRef Medline

33. Ziegelitz D, Arvidsson J, Hellström P, et al. In patients with idiopathic normal pressure hydrocephalus postoperative cerebral perfusion changes measured by dynamic susceptibility contrast magnetic resonance imaging correlate with clinical improvement. J Comput Assist Tomogr 2015;39:531-40 CrossRef Medline

34. Tullberg M, Hellström P, Piechnik SK, et al. Impaired wakefulness is associated with reduced anterior cingulate CBF in patients with normal pressure hydrocephalus. Acta Neurol Scand 2004;110: 322-30 CrossRef Medline

35. Klinge PM, Brooks DJ, Samii A, et al. Correlates of local cerebral blood flow (CBF) in normal pressure hydrocephalus patients before and after shunting: a retrospective analysis of $[(15) \mathrm{O}] \mathrm{H}(2) \mathrm{O}$ PET-CBF studies in $\mathbf{6 5}$ patients. Clin Neurol Neurosurg 2008;110: 369-75 CrossRef Medline

36. Tullberg M, Ziegelitz D, Ribbelin S, et al. White matter diffusion is higher in Binswanger disease than in idiopathic normal pressure hydrocephalus. Acta Neurol Scand 2009;120:226-34 CrossRef Medline

37. Jeppsson A, Höltta M, Zetterberg H, et al. Amyloid mis-metabolism in idiopathic normal pressure hydrocephalus. Fluids Barriers CNS 2016;13:13 CrossRef Medline

38. Nakajima M, Miyajima M, Ogino I, et al. Cerebrospinal fluid biomarkers for prognosis of long-term cognitive treatment outcomes in patients with idiopathic normal pressure hydrocephalus. $J \mathrm{Neu}$ rol Sci 2015;357:88-95 CrossRef Medline

39. Ringstad G, Vatnehol SA, Eide PK. Glymphatic MRI in idiopathic normal pressure hydrocephalus. Brain 2017;140:2691-705 CrossRef Medline 